\title{
EL ARGUMENTO COMO COGNICIÓN PRÁCTICA: ESQUEMAS Y PATOLOGÍAS DISCURSIVAS
}

\author{
Emilio Rivano Fischer
}

\begin{abstract}
RESUMEN
Este artículo revisa algunos esquemas de razonamiento práctico. Los expresa en términos del modelo de "lógica práctica" de Toulmin. Sin embargo, estos esquemas no son tratados como normas o procedimientos (legales), sino como mecanismos cognitivos. Se introduce la idea de que las metáforas son garantías o licencias argumentales. Un propósito general del artículo es el de introducir herramientas prácticas para la evaluación y para la producción de afirmaciones y propuestas cotidianas.

Palabras clave: Argumentación, razonamiento práctico, cognición, metáfora, esquema.
\end{abstract}

\begin{abstract}
This article overviews some schemes for practical reasoning. It expresses them in terms of Toulmin's model of "practical logic". The schemes, though, are treated not as norms or (legal) procedures, but as cognitive mechanisms. It introduces the idea that metaphors are guarantees or argumentative licenses. A general purpose of this article is to introduce practical tools for assessing and for producing everyday claims and proposals.
\end{abstract}

Key words: argumentation, practical reasoning, cognition, metaphor, scheme.

\section{El argumento}

\subsection{Notas preliminares}

Hay racionalidad en las cosas, pero no a la manera de Aristóteles, como una racionalidad en el mundo y una racionalidad del mundo. El mundo no tiene racionalidad. Es lo que es. La

Dr. Emilio Rivano Fisher. Doctor en Filosofía de la Universidad de Lund. Docente de la Universidad de Stanford. Sede Santiago de Chile.

Correo electrónico: erivano@juno.com

Recepción: 28-01-2010

Aceptación: 3-03-2010 
racionalidad está en la mente (en los asuntos del hombre y de las otras mentes del mundo orgánico). Los argumentos son secuencias básicas, trozos moleculares de racionalidad. El argumento es un proceso cognitivo, un mecanismo subyacente que produce conclusiones.

Importa indicar que no sabemos nada sobre posibles correspondencias neurológicas de esto que llamamos argumento. No tenemos conocimiento sobre el cerebro humano como para enfrentar este tipo de preguntas. Por otro lado, aunque supiéramos lo suficiente como para describir lo que ocurre con las neuronas cuando argumentamos, aún así necesitaríamos una teoría que ubicara esos datos en un plano explicativo que les diera algún sentido, de modo tal que los datos formaran parte de una explicación de lo que sí sabemos sobre el argumento en los usos lingüísticos humanos.

Nuestro conocimiento del argumento se recoge de evidencias lingüísticas y otras en la conducta de las personas. Ese es el tipo de objeto que interesa al estudio del argumento. Cuando los haya, los enunciados neurológicos y otros sobre estados cerebrales al momento de producirse el argumento, interesarán en la discusión de ciertos procesos causales, pero no interesarán en la discusión del argumento en su totalidad.

Podemos vislumbrar los tipos de computaciones (mentales) que dan cuenta de la variedad infinita de conclusiones que producimos los humanos. En parte, vemos en la lógica aproximaciones sistemáticas a la "gramática" de la argumentación. Sin embargo, la lógica no estudia racionalidad de hecho, sino formal, inmaterial. El recorrido que haremos será otro. Interesa en estos desarrollos comentar el argumento en su manifestación esquemática; observarlo en sus formas aplicadas, no en forma matemática o abstracta. Interesa describirlo allí donde las conductas de los individuos están implicadas. Esbozaremos el argumento como cognición práctica.

En este contexto, como se entiende, toda indicación a una patología no se refiere a un problema neuronal u otro fisiológico, sino a "inadecuación" o "malfuncionamiento" argumental, es decir, problemas de aplicación de algún esquema cognitivo. (La bibliografía relacionada con estos temas es considerable. Enfoques como los de Piaget, por un lado, en los que las estructuras cognitivas se gestan a partir de la interacción del individuo con su medio, y los de Fodor, por otro lado, con un "lenguaje" de la mente, representan posturas relativamente claras y contrapuestas que pueden guiar primeras lecturas. Abundan textos más actuales, e.g. The Nature of Reasoning (Leighton \& Sternberg(eds.) 2004); Human Reason:The Psychology of Deduction (Evans, Newstead, Byrne (eds.) 1993), Thinking and Reasoning (Marktelov 1999), Perspectives on Reasoning and Thinking (Newstead and Evans 1995)).

\subsection{Articulación del argumento}

Algo ocurre entre evidencia y conclusión (entre dato y sentencia, hecho y resolución, experiencia y sugerencia, información y propuesta, circunstancia y valoración, acontecimiento y llamado a la acción, condición y admonición, antecedente y consecuencia, testimonio y acusación, antecedentes y sentencia, etc.), de modo tal que las partes se unen y la segunda parte, que no era algo dado, queda firme en nuestros sentidos. A esta serie de pares que despierta nuestra intuición inicial podemos llamar fundamento y afirmación, respectivamente. Suele llamarse a lo que ocurre, al vínculo que se produce entre el fundamento y la afirmación, "razonamiento" y también "inferencia". Al complejo total que se produce podemos llamar "argumento". 
Lo que observamos es, por un lado, la evidencia (que es el dato, lo empírico, lo que se rescata del mundo de los hechos, lo dado, la materia prima) y, por el otro, la conclusión (que es el producto, el acto lingüístico de propuesta del caso). "Entre" la evidencia y la conclusión debemos suponer un mecanismo de producción. Es lo que llamamos un mecanismo de cognición práctica.

Adaptamos del modelo de lógica factual de Toulmin (1958) para darle forma a este mecanismo. Allí hay una articulación que define la operación y precisa la totalidad. (Ver también Rivano, J. 1984; Rivano E. 1999; Rivano E. 2004). Las partes principales de este modelo son: (a) datos, (b) garantía, (c) apoyo, (d) conclusión. Podemos verlo como un molde general para montar y desmontar argumentos. Los datos son los hechos, la evidencia, lo dado, o aquello que se da por hecho; la garantía es el principio general que me permite ir desde los datos a la conclusión; la conclusión es el producto del mecanismo, lo que se busca o se logra, que puede ser una propuesta, una insinuación, una opinión, un llamado a la acción, una afirmación cognoscitiva, entre incontables propósitos de racionalidad en contexto; el apoyo es la fuente desde la que surge la garantía, el contenido factual o sustancial que justifica el principio general que ésta expresa.

Cualquier acto de habla que en términos comunes califique como propuesta, insinuación, recomendación, afirmación, conclusión, apreciación, opinión, advertencia, exhortación, consejo, entre otros, puede proyectarse en el modelo para una primera visualización. Todos estos tipos de actos de habla son productos argumentales. (Por otro lado, como vemos, no sólo actos de habla, sino comportamientos y actitudes pueden igualmente ser productos del mecanismo argumental). El modelo articula las partes del argumento y nos permite pronunciarnos sobre su funcionamiento.

\subsection{Partes del argumento}

En general, a estos productos se les llama conclusiones, en el sentido de puntos finales de algún proceso de inferencia. Nos encontramos con un conjunto abierto de tipos: afirmaciones generales ("los profesores son mal pagados"), juicios valóricos ("es bueno que la familia permanezca unida"), afirmaciones sobre eventos ("el país ha iniciado un proceso de desarrollo educacional"), llamados a la acción ("debemos salir todos a votar el día de las elecciones"), adscripción de atributos o de propiedades ("el vecino padece de insomnio", "las hormigas poseen un sistema químico de señalización"), entre incontables otros. La conclusión es el producto final del mecanismo argumental.

Si comparamos la información de los datos con la de la conclusión, advertimos que la conclusión va más allá de los datos. Ilustremos:

Dato: Argentina está comprando gas natural a Bolivia

Conclusión: Los argentinos están aumentando su consumo energético

Para llegar más allá de los datos, el proceso ha hecho escala en una garantía, que subordina los datos a un principio general:

Garantía: si un país compra energía adicional es porque la requiere para el consumo adicional de su población.

Si se acepta la garantía, la conclusión se sigue de los datos. Como hemos dicho, los elementos de un argumento, así como se articulan en el modelo, no siempre están explícitos 
en la argumentación de hecho. Más bien, suelen no estarlo y aparecer el elemento "conclusión" o "propuesta" solamente, que es el propósito final del argumento, el producto del mecanismo. Otras veces aparece el dato y la conclusión se hace obvia. Por ejemplo, de regreso a casa con mi hermano nos preguntamos si habrán vuelto nuestros padres: - La luz de su dormitorio está encendida-, comenta mi hermano. Es un dato, una observación puntual; pero su función es fundamentar una conclusión en torno al tópico de la conversación: han llegado nuestros padres. Esta conclusión no ha sido expresada. Se infiere del contexto. En general, la garantía se presume como algo que la audiencia conoce y está dispuesta a aportar automáticamente. En este último caso, que, si hay luz en el dormitorio de los padres es porque ellos están en casa, el apoyo de esta garantía es la experiencia que poseemos los hermanos participantes sobre esos hechos.

\section{Esquemas de cognición práctica}

Revisemos algunos esquemas de cognición práctica, anotando, desde ya, que se trata de un número abierto de formas que acá articulamos y comentamos apoyándonos en las categorías funcionales del modelo.

\subsection{Inducciones}

Se llama inducciones a ciertos mecanismos de producción de conclusiones en los que se va desde casos particulares a generalizaciones, desde ejemplos a tipos, desde rasgos a descripciones generales. Entre los productos de esos esquemas, resaltan las calificaciones o descalificaciones comunes. Las características de uno o algunos casos se proyectan a tipos generales o categorías. Sobre la base de esos ejemplos, se sostiene que esas categorías poseen esas características. La categoría cubre toda su extensión, todo miembro suyo, más allá de los ejemplos desde los que se partió. "Perro", "familia de clase media", "burócrata", "académico", "taxista" son términos que nombran categorías. Estos esquemas o formas de razonamiento constituyen mecanismos para producir juicios de todo tipo en los que se cultiva con facilidad la descalificación liviana, la generalización apurada, el prejuicio y otras patologías discursivas.

La garantía o principio de inferencia en estos esquemas implica o, de hacerse explícita, asevera que las características descritas en el caso ejemplar o concreto, se encuentran igualmente en los otros miembros de la categoría. Por ejemplo:

"El otro día me subí a un bus y el conductor insultó con indecencias a una señora y ayer andaba en otro bus y el conductor se puso a contar chistes picantísimos con una amigo a toda voz. ¡Los conductores de buses son unos groseros insolentes de porquería!"

La cita nos entrega dos casos, algo distintos el uno del otro, con ciertos rasgos de lo que se describe allí como "grosero", que es el predicado de la conclusión y es la calificación que ahora abarca a todos los miembros de la categoría "conductor de bus". Es decir, la afirmación nos dice: escoja usted un individuo conductor de bus, pues bien, es un grosero de porquería. De dos casos particulares saltamos a todo caso.

El enjuiciamiento que trae esta conclusión no está justificado. Observamos, no obstante, la fuerza de este esquema en tanto inercia cognitiva y su peligrosidad en tanto arma retórica: para manchar, arruinar, descalificar o degradar a una clase completa de individuos, basta exponer un par de miembros con características negativas de la clase y adjudicarle esas características a la clase entera. 
Notemos que, como todo otro, este esquema de cognición práctica no es, en sí, patológico, sino su aplicación en la situación esbozada. Los esquemas son funcionamientos inmediatos. Producen racionalidad local. El cuestionamiento gira en torno a la calidad de esa racionalidad. Si una madre sabe de dos casos de papas envenenadas en su ciudad, está plenamente justificada en concluir que las papas (en general) están envenenadas y evitar comprarlas para alimentar a sus hijos hasta que pase la alerta.

\subsubsection{Nuevos comentarios: la calidad de los ejemplos}

Desarrollemos un poco más sobre este tipo de esquema argumental: de ejemplos a generalizaciones. Un primer asunto que surge suele ser sobre la veracidad de los datos o los ejemplos. Veamos un caso, que adapto y reelaboro de Weston (1992):

"Antes, las mujeres comenzaban su vida adulta siendo más jóvenes que ahora:

Mira, mi abuelita se casó a los quince y mi madre a los dieciséis; en Romeo y Julieta, Julieta no tenía catorce y ya estaba en esas; las romanas de la época del Imperio se casaban a los trece o catorce, y la Virgen María tenía catorce años cuando tuvo a Jesús."

Este argumento se fabrica sobre la base de 5 casos: dos de ellos concretos y de la experiencia, uno ficticio por ser de una obra clásica, el cuarto es un dato histórico genérico y el último, un dato histórico individual. La forma general del argumento es:

\section{Premisas (o datos):}

Mi abuela se casó a los 15 años

Mi madre se casó a los 16 años

Julieta tenía 13 años cuando vivía sus amoríos con Romeo

Las romanas se casaban a los 13 o 14 años

María tenía 14 años cuando tuvo a Jesús

\section{Conclusión:}

Luego, en contraste con lo que ocurre en la actualidad, antes las mujeres iniciaban su vida adulta siendo más jóvenes.

La forma general de este tipo de argumentos y su revisión, como siempre, consiste en establecer la calidad del mecanismo que hace saltar de las premisas a la conclusión. Pero, antes de revisar el mecanismo en sí, debemos establecer la calidad de los datos, porque se nos ofrecen como algo dado, real, verdadero; pero, ¿son los datos verdaderos? Ese es un requisito implícito en el argumentador, el cual debe revisarse en primer lugar. Sobre María, la madre y la abuela del argumentador podemos conceder el punto, pero ¿es Julieta un dato válido? Y, principalmente, ¿cómo se ha establecido que las romanas se casaban en su mayoría entre los trece y los catorce años?

\subsubsection{El mecanismo}

Suponiendo que los datos son veraces, procedemos al mecanismo. Dados los datos y la conclusión, el mecanismo se reduce a la garantía y su apoyo. Opera la siguiente garantía específica (la premisa mayor): lo que es verdad de una abuela, una madre, un personaje en una 
obra literaria, las mujeres del Imperio Romano en general y una mujer judía del Siglo Primero (considerada por muchos la madre de Dios), también lo es de todas las mujeres de antes (del pasado.) Dada una garantía así, nos preguntamos cuál es su apoyo. No hallándolo, se abre la crítica total al argumento del caso. Se nos manifiesta nuevamente una patología argumental: ¿Es esa muestra representativa de las mujeres de antaño, en general? ¿Hay criterios para establecer una muestra representativa en este plano? ¿Hay acaso otros grupos de mujeres en la historia que no se casaban en su primera adolescencia? ¿Qué quiere decir el argumento con "antes" -antes de qué, antes desde cuándo, antes hasta qué punto en la historia, antes en qué lugar-?

De modo que, tanto al fabricar este tipo de argumentos como al analizarlos, conviene calibrar el valor de los ejemplos en el marco del principio general. Es posible que los ejemplos sean indicios de algo, pero que sean el fundamento o justificación de la conclusión es asunto distinto.

\subsubsection{Más es mejor}

Esta suerte de instrucción metafórica aplica claramente en retórica. No pocas veces, conviene a quien argumenta alimentar su conclusión con más ejemplos. Readapto el caso siguiente, nuevamente de Weston (1992):

"Las mujeres tuvimos que luchar por nuestro derecho al sufragio. Cuando las mujeres luchan, consiguen sus derechos. Y por eso es que tenemos que luchar para lograr que se legalice el aborto en Chile."

Es frecuente esta figura en la que aparece un ejemplo y una conclusión apurada. Más de una buena causa, se pierde por esta flojera argumental, por resultar demasiado débil el fundamento de la conclusión. Probemos mejorar nuestra propuesta:

"El derecho al sufragio femenino se logró luego de una lucha; el derecho a la educación superior institucional femenina se logró luego de una lucha; el derecho a igualdad ante el empleo entre los sexos se logró después de una lucha; por eso, luchando, lograremos el derecho al aborto"

Esta última versión es un poco más contundente. Presenta más casos similares, lo que amplía su calidad y, suponemos, produce mayor convicción. Las conclusiones no son exactamente iguales, pero el llamado es equivalente.

Advirtamos que ambas versiones tienen algo de "naturaleza de las cosas", de modo que, realmente, no requieren probarse mayormente. Pero, el contexto que podemos imaginar es de agitación política o popular, de modo que interesa motivar a la audiencia a la acción, a la lucha. Lo que se dice es que nada viene de la nada, sino que es necesario hacer que ocurra, hay que trabajar para el logro, hay que luchar para obtener el derecho, la justicia, el poder. Es una obviedad, pero no en el contexto de llamado a la acción que interesa. Es decir, no interesa la obviedad intelectual del argumento, sino su fuerza para producir acción. Como vemos, el número de ejemplos es tan reducido como el número de ejemplos de mujeres madres en temprana edad. Pero, las argumentaciones pertenecen a campos distintos -edad de parto en las mujeres a lo largo de la historia, por un lado, logros a través de la lucha política de las mujeres a lo largo de la historia, por el otro-; pero, particularmente, estas argumentaciones buscan propósitos distintos -el conocimiento y la acción, respectivamente-. Podríamos considerar ejemplos múltiples y trágicos de luchas fracasadas por derechos a lo largo de la 
historia, sin que con ellos restemos fuerza al llamado que revisamos. En cambio, revisando un número de contra ejemplos en la edad de parto de mujeres a lo largo de la historia, restamos fuerza o invalidamos ese otro argumento.

De modo que hemos entrado en el plano de los motivos y la acción, alejándonos del plano de las razones y la reflexión; porque, en términos del número de ejemplos provistos para la conclusión del caso, vemos que distintos argumentos pueden presentar una calidad similar. Pero, en el caso del llamado a la lucha por el derecho al aborto, nos movemos en un plano de acción y hay principios morales y fuerzas políticas de fondo.

\subsection{Esquemas de derivación causal con rasgos analíticos}

En estos argumentos, se propone una relación causal entre dos fenómenos o estados de cosas, de modo tal que del primero se deriva el segundo. Se establecen, así, garantías en las que se asevera que ciertos eventos se siguen de otros por vínculo causal entre ambos: el primero causa al segundo. Si bien el producto o conclusión de estos argumentos es una garantía, el mecanismo interno de cada uno de ellos tiene una garantía propia, distinta a la conclusión producida. Como ocurría en las generalizaciones anteriores, de ejemplos a generalizaciones, la conclusión en estos argumentos trata de un aspecto del tipo o categoría implicada en el evento o los eventos desde los que se parte. Se sostiene, por ejemplo: "Las señalizaciones del tránsito son el factor principal de ordenamiento del flujo vehicular". Vemos que esta propuesta es una garantía, es decir, un principio de inferencia, que podríamos reformular, por ejemplo, como "si algo es una señalización del tránsito, entonces es un factor en el ordenamiento vehicular", o bien, "toda señalización del tránsito es factor causal en el ordenamiento vehicular". La conclusión selecciona un aspecto del estado de cosas "señalizaciones del tránsito" para concluir desde allí "ordenamiento vehicular" en forma causal general. Entre otras cosas, algo hay en el fenómeno complejo de las señalizaciones del tránsito que se relaciona con el fenómeno complejo del ordenamiento vehicular. A esta selección y la relación causal que produce llamamos "derivación causal."

¿Cómo se ha llegado a la generalización causal? ¿Cómo se estableció el aspecto seleccionado? Alguien podría justificar este principio del siguiente modo: "En las señas para el tránsito vehicular se indica lo que está permitido hacer y lo que no está permitido hacer en los distintos lugares. La simbología se enseña a todos los conductores, de modo tal que todos conocen las normas que rigen. Por eso es que las señalizaciones del tránsito son el factor principal de ordenamiento del flujo vehicular" El argumento se ha hecho a partir de rasgos o aspectos más bien formales o analíticos del complejo "señalizaciones del tránsito", aunque se menciona la enseñanza de la normativa, que es al menos en parte algo sustancial. Pero, expuesta a una revisión mínima, difícilmente nos convence esa caracterización, si bien es muy común que ese sea el tipo de diseño detrás de estas propuestas y que esa mínima revisión nunca se produzca. Un principio causal en este tipo de fenómenos debe emanar de estudios que detecten correlaciones claras en los hechos (o datos empíricos, como se les llama.) Por ejemplo, estudios que comparan la situación en lugares bien señalizados y otros mal señalizados. Quizás el exceso de señalización confunda... Como siempre, esa no suele ser la calidad que presentan estos argumentos en la vida pública.

Como otras de este tipo, esta conclusión presenta un aspecto que, de algún modo, parece existir o estar implicado en el evento desde el que se parte; un aspecto que parece haber sido seleccionado de las premisas mismas. 


\subsubsection{El recogido de basura}

Estos argumentos que llamamos de derivación causal con rasgos analíticos producen conclusiones que son garantías, es decir, principios generales que pueden servir en nuevas computaciones. Otro ejemplo: "un sistema moderno de recogido de basura produce una baja en el número y en la intensidad de las enfermedades infecciosas en la población” Esta es una propuesta aparentemente más sustancial. Pero ¿cómo hemos llegado a esta generalización? ¿Cuál es su apoyo? Si lo hemos hecho por pura lógica, nuevamente estamos en la especulación vacía que formula un principio aparentemente causal.

Independientemente de su calidad o sustancia, estas conclusiones, decíamos, son garantías que nos permiten computar en forma adicional. Por ejemplo, alguien propone: "si se instala un servicio moderno de recogido de basura en las otras comunas, se obtiene una baja en la cantidad de enfermedades contagiosas en la población" o "entre las medidas para el mejoramiento de la salud pública que propongo cuando sea el nuevo alcalde está la modernización del sistema de recogido de basura, porque, como se sabe, esto tiene por efecto una baja en el número y en la intensidad de las enfermedades infecciosas en la población".

\subsection{2. ¿Relación causal o palabrería?}

Si bien la conclusión que producen es una garantía, el énfasis en estos argumentos puede estar en ese principio general o en la causa o en los efectos, dependiendo de lo que interese. Es decir, el interés podría estar en la formulación del principio causal para su conocimiento, o para instruir o ilustrar, por ejemplo; o bien, en la causa, para su implementación o eliminación; o bien en el efecto, para elaborar sobre él.

En el caso de las generalizaciones descriptivas a partir de ejemplos, la caracterización encontrada en los ejemplos se extrapolaba a todos los miembros de la categoría. De modo que la relación establecida en la generalización era de inclusión: el rasgo estaba en todos los miembros. Los miembros estaban incluidos en la clase que el rasgo denotaba (e.g. las universidades son estafas, los gitanos son ladrones, los políticos son embusteros, etc.). En cambio, en los esquemas que producen derivación causal desde un evento o fenómeno complejo hacia un efecto suyo, o desde efectos hacia los eventos que los causan, se supone que no hay una concomitancia puramente descriptiva entre los datos y la conclusión, sino una relación o vínculo causal, una concomitancia en los hechos. La forma de presentación es: esto causa esto otro. Se implica que se trata de dos cosas distintas. Como hemos mencionado, debemos prestar atención y establecer si realmente se trata de asuntos distintos y fenómenos causalmente vinculados, o de pura palabrería. El recogido de basura es una cosa, las enfermedades infecciosas, otra. Si se afirma un vínculo causal entres ambas, el asunto requiere de estudios varios e informes serios. Pero, si con el término "basura" se está subentendiendo "infección”, la relación que se propone es puramente formal, semántica. Y nos enteramos, ya demasiado tarde, que el nuevo recogido de basura que se pretende es la empresa del sobrino del alcalde.

\subsection{Esquemas de causas a efectos}

Como los anteriores, estos argumentos proponen garantías que sostienen una relación causal o de concomitancia entre dos estados de cosas. Formas de expresar esta relación son: (a) un estado de cosas, B, se sigue de otro estado de cosas, A; (b) siempre que existe A se produce 
también B; (c) A causa B. Pero, a diferencia de los anteriores, en estos esquemas no hay una selección de un aspecto de uno de los lados de la relación para establecer el otro, lo que hemos llamado "derivación causal", ni hay una mera concomitancia descriptiva o nocional entre las partes. La relación causa-efecto, propiamente, no es una de inclusión o de identidad entre los lados involucrados. Es decir, la causa y el efecto no están relacionadas intrínsecamente; no hay en la naturaleza del estado de cosas, que es la causa, algo que es o debería ser el estado de cosas, que es lo causado.

Por esta relación de causa y efecto entre A y B, cada vez que se da A puedo inferir la aparición de B. De modo que estos argumentos predicen estados futuros sobre la base de estados actuales.

\subsubsection{El aborto}

Esbocemos un par de argumentos de este tipo:

(1) Si legalizamos el aborto removeríamos la causa principal de muerte por efecto de derrame sanguíneo, infección interna y shock en la población femenina entre los 15 y los 45 años. El número de mujeres que han recibido un aborto ilegal con complicaciones de este tipo es alarmante. Comparado con números de intervenciones legales de similares características, podemos constatar que estos últimos procedimientos son 98\% seguros, contra un $30 \%$ de complicaciones y un estimado $5 \%$ de desenlaces fatales en las intervenciones ilegales. Por ello, el Partido por la Libertad (el PPL) propone legalizar el aborto.

(2) El sistema de asignación por infante a la madre equivalente a una pensión vitalicia mensual que propone el Partido por el Bien Común (el PPBC) disminuirá el número de abortos ilegales en el país. Actualmente, el número estimado de abortos anuales en el país es de 240.000. En las encuestas realizadas por la agencia independiente COMA Y PUNTO, 6 de cada 10 encuestadas que se habían hecho al menos un aborto en su vida declararon que el factor principal de su decisión fue la incertidumbre económica que un hijo le producía. De este modo, la nueva ley hará que disminuyan considerablemente los abortos.

Como vemos, el efecto en estos argumentos no es un aspecto de la causa, sino un fenómeno aparte, distinto. Como en los otros casos, la aplicación del modelo es un procedimiento claro para evaluar estos argumentos. Puntos que requieren atención en la evaluación de este tipo de argumentos giran en torno a cuestiones como: (a) ¿es la relación causal que la garantía afirma altamente probable, dados sus lados componentes?, (b) ¿confirman los casos específicos entregados la garantía? (c) ¿concuerdan los datos entregados con la garantía?, (d) ¿hay otros factores que puedan interferir con el efecto?, (e) ¿hay otras causas probables para los efectos del caso?

\subsection{Analogías}

El esquema general en este tipo de argumentos es la similitud entre dos eventos. Se sostiene que, basado en esa similitud, aquello que se ha concluido para el primero también podrá concluirse para el segundo. 


\subsubsection{Legalizar la Marihuana}

Veamos este ejemplo:

"La legalización de la marihuana en Holanda ha eliminado el tráfico ilegal de ese estupefaciente sin incrementar su uso en la población. Por ello, debemos legalizar también en Chile la venta de marihuana."

En este caso, la garantía general es que, dado que los eventos o situaciones del caso son similares en el detalle de sus relaciones y propiedades, lo que se ha producido a partir de una, igualmente se producirá a partir de la otra.

La similitud postulada y las consecuencias de la situación dada son datos en el esquema básico del caso. La garantía es que lo que ha caracterizado o se ha concluido, inferido o producido de hecho en la situación dada, puede caracterizar o concluirse de la situación hipotética, por la similitud de fondo.

Se ha destacado desde antiguo el potencial retórico de este tipo de argumentos. En efecto, una vez concedida la similitud de fondo, cualquier propiedad, aspecto, consecuencia, o fenómeno asociado a la situación dada puede ser concluido de la situación hipotética, sin mayor inspección crítica. En el caso anterior, podría, por ejemplo, el argumentador interesado, continuar con consecuencias o rasgos positivos de la legalización en Holanda: "habrá, así, transparencia sobre los flujos monetarios de esta actividad", "habrá recolección de impuestos por la actividad económica de compra y venta del producto", "habrá claridad sobre el consumo de esta sustancia", "habrá control sanitario sobre el producto y su consumo", etc.

En lo que a la dinámica del diálogo respecta, vemos que estos argumentos tienden a traspasar el peso de la prueba a un ámbito o participante que suele no tenerlo. En un intercambio normal, el peso de la prueba lo tendrá quien plantee que el estado de cosas debe alterarse. Es decir, el status quo descansa, por así decirlo, en su propia inercia. No necesita estar probándose. Por ejemplo, si dos partes comparecen ante un tribunal porque una alega que el cerco de la casa del vecino pasa por su propiedad, es este último quien debe demostrar la acusación, ya que el cerco de hecho existe en el lugar previamente. Para removerlo se requiere de argumentación, un proceso jurídico y un dictamen. Para dejarlo, no se requiere nada.

Otro caso tipo: Si alguien es acusado de haber maltratado a otro, éste podrá descansar en la presunción de inocencia: la acusación tiene el peso de la prueba.

En ciertas argumentaciones por analogía - como el caso de la legalización de la marihuana en Chile atendiendo a la situación en Holanda-, constatamos que el status quo en Chile de pronto se ve empujado a justificarse. El argumento por analogía es una estrategia eficaz para traspasar la obligación de probar un asunto a la parte que, en principio, no la tiene. En este ejemplo, de pronto una parte debe justificar el hecho de que en Chile la venta de marihuana es ilegal.

La garantía en este tipo de argumentos es que las mismas relaciones, consecuencias, características aplican en ambos lados de la analogía y, por ello, lo que se ha establecido para un lado, puede también concluirse para el otro. Basada en lo anterior, la argumentación analógica descansa, por así decirlo, en la parte que ya está establecida, los beneficios de la legalización de la marihuana en Holanda, para proponer algo sobre la parte no establecida, el estado de ilegalidad de la marihuana en Chile y la ausencia de esos beneficios. 


\subsubsection{Terroristas}

Veamos otro tipo de ejemplo de argumentación analógica atendiendo al potencial de concomitancia que importa: "El movimiento mapuche Maputún ha sido calificado como "un grupo terrorista" por el Consejo de Seguridad Nacional del Estado (CSN). El Maputún ha declarado ser "un movimiento por la independencia del pueblo mapuche". Por su parte, el movimiento mapuche Chenguei igualmente ha declarado "ser un movimiento por la independencia del pueblo mapuche". El articulista Pedro de Valdivia, del diario "La Pacificación”, concluye en un artículo que, "al igual que el Maputún, que ha sido catalogado como terrorista por el CSN, el Chenguei también es un movimiento terrorista, porque ambos proponen la independencia del pueblo mapuche."

El argumento es algo torpe, pero su calidad y naturaleza no deja de abundar en la prensa y por doquier y de persuadir y provocar adhesión en la audiencia dormida. Como se aprecia, la propuesta se basa en la identidad de un fragmento de lenguaje entre dos grupos políticos y la calificación de terrorista que se ha hecho de uno de ellos por parte de una instancia autorizada. Es una variante del "dime con quien andas y te diré quien eres". En este caso: ya que te vimos lucir el mismo tipo de poncho que ese que es terrorista, entonces tú también lo eres.

\subsection{Argumentos con garantías metafóricas}

En estos argumentos, la similitud postulada entre los eventos del caso es abstracta o estructural, no "real". Es decir, no se parte del supuesto de que los eventos son "lo mismo" en tanto tipos de hechos. Más bien se pretende que un evento, el de origen, es revelador de un aspecto clave del evento del que trata la conclusión.

\subsubsection{Leigh: el comunismo es un cáncer}

Por ejemplo, en los primeros años de la dictadura militar en Chile escuché al General Leigh declarar por los medios que "el comunismo es como un cáncer y hay que extirparlo de raíz." Analicemos lo que se implica:

Dato: el cáncer se expande en el cuerpo

Dato: el cáncer es dañino y fatal

Dato: el cáncer es tratable

Dato: el cáncer se extirpa para curar al enfermo de cáncer

Dato: El comunismo se expande en la sociedad

Dato: El comunismo es dañino a la sociedad lo que el cáncer al cuerpo

Dato: El comunismo es a la sociedad lo que el cáncer es al cuerpo

Conclusión: para curar a la sociedad del comunismo, debemos extirparlo

Garantía 1: La sociedad es como un cuerpo (Metáfora)

Garantía 2: Si se puede extirpar el cáncer del cuerpo, también se puede extirpar el comunismo de la sociedad

Como vemos, la metáfora es un arma retórica de peso. Por otro lado, observamos que estos esquemas no traen apoyo, porque más que concluir sobre hechos, concluyen sobre maneras de ver lo hechos y, en base a éstas, sobre maneras de obrar. De modo que estos argumentos, puede decirse, no "prueban" lo que proponen. Son armas sutiles, efectivas, muchas veces peligrosas y, en general, subrepticias en las contiendas discursivas. 


\subsubsection{El alimento educativo}

Otro ejemplo:

"La docencia es el alimento que hace crecer el conocimiento en nuestras escuelas.

Por ello, debemos aumentar el número de horas docentes en los recintos escolares de enseñanza primaria para hacer crecer el conocimiento en nuestros niños."

Como vemos, las metáforas pueden resultar peligrosas. También, pueden resultar tendenciosas y sedativas. Si aceptamos sin cuestionamiento que la educación es alimento espiritual (nutrición del intelecto, etc.), estaremos dispuestos a que se aumente la jornada escolar en nuestras escuelas. De hecho, veremos ese incremento como un regalo a nuestros hijos. Pero, probemos otra perspectiva. Cambiemos la metáfora: La educación no es alimento. La educación es una cárcel: Las escuelas y lo que allí ocurre es actividad y procedimiento carcelario. Cambiando por la imagen de una cárcel aquel atuendo metafórico de la nutrición del espíritu, y otros ropajes atractivos que se le cuelgan, la educación se ve de otra manera. La metáfora de la educación como cárcel, especialmente en la periferia del tercer mundo, nos llama a ver el recinto de custodia de los niños mientras los padres trabajan. La imagen se ajusta mejor a buena parte de la realidad de nuestros países latinoamericanos. Como es sabido, en estos recintos "educacionales" los niños están encerrados, incómodos, son muchas veces maltratados, se desarrollan defectuosamente y pierden buena parte de su precioso tiempo de niñez. Más que un alimento nutritivo para el espíritu, entonces, la educación en esas circunstancias asemeja una cárcel.

Las metáforas, entonces, pueden también resultar reveladoras y beneficiosas. Así es como en las ciencias, en las técnicas, en la administración, en la gestión, en la organización, nos encontramos a menudo con "modelos" para el entendimiento de los fenómenos o el procedimiento práctico. Por ejemplo, se logra un primer entendimiento al ver el átomo como un sistema gravitacional "planetario"; se logra un entendimiento y un procedimiento al ver el flujo vehicular como un flujo de líquidos por conductos o canales; otro tanto ocurre con la electricidad, que se colma de términos tomados del procesamiento del agua (acumulación, corriente, tapones, presión); se logra un entendimiento y eventuales maneras de relación cuando se habla de una organización "vertical" y otra "horizontal"; etc. La analogía tiene un alcance, un límite pasado el cual, ya no aplica. Pero, puede ser provechosa para introducir e instruir en terrenos difíciles o desconocidos y para enfocar desde distintas perspectivas un fenómeno. Son los temas de la metáfora.

Por otro lado, como también hemos visto, una inspección crítica de una analogía revela sus debilidades: siempre que hay dos situaciones complejas, éstas tendrán aspectos análogos y otros que no lo son. De modo que, al exigir firmeza en la garantía del caso por vías de su apoyo, nos encontramos con que es muy difícil llegar a un término en el asunto, si la otra parte insiste en las diferencias. Un interlocutor podrá insistir en que los efectos de las disposiciones legales en los países son fenómenos estables y predecibles, por lo que la comparación de la situación en Holanda y en Chile es legítima, en tanto que el otro insistirá en que los efectos de disposiciones legales en culturas distintas son también distintos. Ambas partes encontrarán apoyo a sus principios y difícilmente se llegará a una inclinación por un lado o por el otro en términos racionales (justificativos), si ambos lados son diestros en la argumentación. En las disputas con argumentos por analogía y por metáfora (o analogía estructural), tenemos una topología de posibles tablas o empate argumentativo. 


\section{Patología argumental por vía metafórica}

Como lo hemos dicho, temas bajo el rótulo de "patología" sólo pueden considerarse como ópticas sugestivas -desarrollos varios para la orientación práctica, indicaciones o preceptos para guiar y alertar el juicio en materia del razonamiento y argumentación-. Detectamos inadecuación e impropiedad, pero, obviamente, no hay estándares firmes ni claros de salud o sanidad en estos terrenos. El nombre es una metáfora llamativa, que apunta a un conglomerado difuso de asuntos. Su revisión nos permitirá desarrollar nuevas perspectivas.

Por patología argumental, podemos entender todo fenómeno de malfuncionamiento argumental. Como hemos visto, no se trata de fallas estructurales en el esquema del caso, sino de problemas de aplicación. El punto nos llama a revisar el terreno mismo, el campo argumental en el que se inscriben las propuestas, demandas, alegatos, juicios valóricos, sugerencias, amenazas, afirmaciones, llamados a la acción, entre otros tipos de actos producidos por los argumentos. Asumiendo un campo argumental como entorno propio de una propuesta, podemos medir su adecuación.

\subsection{Metáfora referencial: Lo dicho es hecho. La hipnosis de las palabras.}

Hemos mencionado la idea de la metáfora como una garantía argumental. Veamos una metáfora general, amplia como el lenguaje mismo y muy dañina a veces. Está en la base de muchas de las críticas de Wittgenstein en torno al supuesto valor objetivo o referencial en el lenguaje.

Es una muy curiosa inercia la de otorgar valor de hecho a algo que está dicho. Esta es una suerte de metáfora referencial profunda, que podríamos nombrar LAS PALABRAS SON HECHOS, LO DICHO ES OBJETIVIDAD o LO DICHO ES HECHO. Es una garantía sutil que se filtra en todo discurso. Aquí mencionamos apenas un par de dimensiones. Un primer reparo que debe hacerse ante cualquier alegato es estar conscientes de que las palabras son una cosa, los hechos, otro asunto muy distinto. Cuando ambos asuntos coinciden, reina la felicidad de la veracidad y la integridad. Pero, más veces que no, hay pathos. De esa patología viven los sofistas, humanistas, intelectuales, políticos, predicadores, charlatanes, embaucadores de todo corte. Citemos del Contra Sofistas:

\footnotetext{
Escucha el discurso del político que anuncia el alza del pan y que en un punto de su discurso dice: "no olvidamos los millares de seres que padecen hambre". Y tú crees lo que dice; y como dice "no olvidamos" piensas tú que de alguna manera padece hambre también el político... Pero el político tampoco olvida que es hora de ir a tomarse un trago. Y en los millones de hogares, donde no quitan los niños el ojo de la cacerola y los ademanes de la madre, hay una atmósfera nueva con matices de cuento de navidad; y todo ello porque hay uno que dice -y además le creen- que él no olvida. (Rivano, J. 1966)
}

Las palabras que uno emite -especialmente sobre asuntos de importancia en los hechos, asuntos de visión moral, de compromiso y acción social, de postura filosófica, de postura humana, de consejo vital, de manifestación de principios de vida, de convicción, de conmiseración y adhesión al "humanismo"- suelen no ser mucho más que el ruido que se produce y las ondas de aire que lo sustentan. La inercia es concederle existencia a las palabras, contrapartida en los hechos a los significados del lenguaje. Y el llamado es a estar alerta contra esta inercia. Esta vez, citemos del Contra Humanistas:

\footnotetext{
Atento el ojo a aquel que te dice "yo soy un humanista." Seguramente le va bien siéndolo, en cuyo caso, su humanismo ya ha perdido buena parte del valor que suponía. Pídele que abandone la mitad de su billetera a la humanidad necesitada -aquel mendigo en el suelo que estira su mano, mientras ustedes se toman
} 
un café-. Y no te digo yo a ti que abandones la mitad de tu billetera en esto o aquello. Te digo que es mejor callar a decir estupideces. Los pocos humanistas que hay, piénsalo, han dado y dado y dado y han perdido hasta sus vidas o están prontos a perderla. Estos últimos nunca te dirán "yo soy un humanista." (Rivano, E. 1999)

La cita nos llama a estar atentos: lo que se dice es una cosa, lo que se hace, otra muy distinta. Cuando lo que se dice suena bonito, noble, ecuánime, ojo, lo más probable es que haya un embaucador detrás de esas palabras. Se escucha, por ejemplo, el alegato ocioso y tendencioso del colega que se autodefine como un defensor de la justicia, de los valores del humanismo, de la probidad, de la dedicación irrenunciable por el prójimo, del compromiso ineluctable por la excelencia académica, del horizonte ineludible por la formación integral del estudiante y otras patrañas. Terminada la reunión del caso, el colega retorna a su oficina y abre apurado su mail para ver cómo anda esa petición de un nuevo computador; ¿han depositado acaso los fondos de ese proyecto de investigación?; ¿por qué hay esa demora en la devolución de la retención de impuestos?; y este descuento en el salario ¿a qué se debe? En fin, el personaje toma café, ríe, retorna a casa y se dedica a sus asuntos, no a los del otro, del destino del estudiante o del prójimo despojado. Cuando alguien sostiene que lamenta profundamente algo, y en ese lamento se anuncia un sentimiento ilustre, altruista, y trascendental, tenlo por seguro, no hay tal lamento, sino sólo engaño, oportunismo, descaro, palabrería.

\subsection{Metáfora del significado: Lo dicho es lo pensado. La hipnosis del sentido de las palabras}

Quizás lo segundo que debemos detectar es esta otra inercia de concederle sentido a las palabras, por el solo hecho de ir pegadas, unidas una detrás de la otra. Se trata de otra metáfora profunda, licencia generosa con la que se trafica de todo en los mercados discursivos. Podemos llamarla de muchas maneras: LO DICHO ES SIGNIFICADO, LO DICHO ES SENTIDO, LO DICHO ES PENSAMIENTO, LO DICHO ES IDEA.

Muchas veces, las palabras que escuchamos en secuencias largas tienen sentido y solemos funcionar bien bajo ese supuesto. Pero, el supuesto puede anestesiarnos completamente. El orador hábil sabe que su público, más veces que no, concederá que hay sentido en lo dicho por el solo hecho de ser dicho. Sobre esa base, puede pasar sus propuestas como conclusiones naturales de lo dicho:

"Lo han sostenido los sabios de Occidente, y también en la sabiduría Oriental nos encontramos con conclusiones que apuntan a esa misma infinitud. Los misterios se han procesado a lo largo de los siglos. Las prácticas venerables de las escuelas ascetas y anacoretas, por ejemplo, los místicos y aquellos antiguos cópticos igualmente apuntan a todo lo que venimos sosteniendo quienes nos inclinamos por las prácticas que cultivamos en nuestros talleres fisiológicoespirituales en la Escuela Alfa-Omega, que atienden al individuo en sus dimensiones cognoscitivo-experienciales y elaboran la creatividad integral, a través del lenguaje y el cuerpo..."

No pocas cabezas de ganado humano transitan diariamente por los corrales de estos laberintos del sinsentido. Citemos un trozo de un texto de "psicología gnóstica" distribuido para su contagio en la población en una sede de esta secta de los gnósticos en la ciudad de Concepción. La "clase" (o fuente epidémica) es sobre hemisferios cerebrales humanos, 
genotipos, fenotipos, psicogénesis, subconsciente, educación. Nos dice este delicioso texto de sinsentido:

"Albert Einstein enunció su fórmula E=mc2. Según Einstein, el principio de la existencia es energía y la materia es energía condensada. El átomo contiene $3 \%$ de materia y $97 \%$ de un espacio vacío que los científicos llaman "vacío" y que los orientales le llaman "Akash" o "éter". Según la ecuación de Einstein, la materia es energía condensada y el principio de existencia con base en la energía, representada en el espacio vacío del átomo, es espiritual".

El asunto sigue y va a dar a la herencia genética, a la educación, al subconsciente en el niño, a la mente criminal, a la corrupción moral. Hagamos una breve escala en la sección de los genes:

"El genotipo se fundamenta en los genes, o sea, la herencia genética está relacionada con la Ley del Karma y los genes están constituidos por cromosomas. En los genes está la herencia paterna y materna. Por la Ley del Karma tendremos los padres que merecemos. En la herencia llevamos los resultados de nuestras malas acciones cometidas en vidas anteriores y, así, los valores negativos de un criminal podrán reencarnar en una familia de criminales, los de un borracho, en una familia alcohólica, los valores místicos, en una familia piadosa, etc. En el subconsciente, expresión de nuestros defectos, llevamos toda esa herencia síquica que determina una herencia biológica”.

Como se dijo, no son pocas las personas que asisten a este tipo de discursos con ingenuidad vergonzosa y salen de la sesión en estado hipnótico, dispuestos a abordar la nave espacial del caso y compartir la buena nueva con el mundo. La garantía o licencia que ha permitido esto, LO DICHO ES SIGNIFICATIVO, no ha sido revisada.

\subsection{Metáfora de la coherencia: La coherencia textual es coherencia real. La función de la construcción de lo real}

Las inercias anteriores son principios generales que aplican a todo tipo de campo argumental, en todo tipo de materias. Veamos ahora un ámbito funcional amplio, pero subeditado a los anteriores, especialmente a la metáfora referencial, y en el que también anidan infinitas patologías.

\subsubsection{Construcciones patológicas de lo real}

La construcción de la realidad es un ámbito de infinitas variantes. Bajo este apartado podemos mencionar un grupo difuso de aberraciones en las que se detectan defectos en la constitución de lo real, relatos inverosímiles o fantásticos de sucesos que se dan por coherentes y por reales. Veamos un ejemplo. Nos dice, por ejemplo, un personaje:

"Se sabe ahora que el templo de Tiotihuaclán era una pista de aterrizaje y despegue para naves extraterrestres: los matemáticos han calculado las coordenadas de los ángulos del templo y están de acuerdo en que se trata de un sistema complejo que guía al navegante galáctico en los vectores que la nave debe adoptar al entrar en la atmósfera terrestre y en la dirección hacia Alfa Centauro en la operación de despegue..." 
Es cierto que, a veces, respuestas como las siguientes se observan ante discursos como el anterior:

a. "¡Vírate, enajenado!"

b. “Sí? Y Machu Pichu era un quiosco intergaláctico que le vendía refrescos tipo diet a los marcianos..."

c. "Yo me viro por la derecha." (Con retirada prudente del campo visual y auditivo del individuo delirante)

Lamentablemente, sin embargo, a la muestra a, b, c, se opone una serie interminable de copilotos intergalácticos.

Este tipo de discurso argumentativo (argumentativo, en que trae propuestas, pretende imponer una visión distinta de la realidad, despliega recursos retóricos persuasivos, apela a la racionalidad de una audiencia, etc.) es más común de lo que suponemos a primera vista. De hecho, mucho de lo que sostenemos a diario guarda una calidad argumental equivalente a la del párrafo que nos entretiene: creencias en prácticas como el Tarot, confianza en distintos horóscopos, señas que se interpretan con certidumbre como mensajes o símbolos o avisos dirigidos a nosotros y a nuestras vidas por fuerzas o entidades desconocidas, creencias religiosas con contenido factual, y mil minucias y necedades que llenan nuestra cabeza y nuestro discurso cotidiano, y que simplemente no se sostienen ante el análisis más elemental de racionalidad en campo alguno bajo criterios que podamos reconocer como pertinentes y autoritativos en la materia.

De modo que esta es una patología generalizada, común como el resfrío, y debemos disciplinarnos en detectarla en nosotros mismos, en primer lugar. Un método articulado de detectación es la aplicación del modelo de análisis a las creencias que damos como certeza, para calibrar su calidad racional. (No se trata, obviamente, de exigir calidad argumental ante afirmaciones que se proponen para "jugar" o para entretenerse, sino asuntos sobre los que estamos dispuestos a iniciar una defensa, o un ataque discursivo y que sostenemos como cosas serias, o asuntos que se nos proponen como cosas serias. Muchas veces nos entretenemos con lecturas de horóscopo, películas de ciencia ficción, especulaciones religiosas, etc. sin dar importancia al asunto y entendiendo que se trata de idioteces o fantasías para pasar el tiempo y satisfacer nuestra imaginación).

\subsubsection{Lo irreal en lo real.}

Tomemos otro ejemplo, muy común, que comienza inquietantemente a incluir un buen número de personas en nuestro entorno social inmediato $\mathrm{y}$, eventualmente, a nosotros mismos. Nos dice este personaje:

"El es el hijo de un dios, de hecho es el hijo de el dios, con una mortal, aunque la mortal no ha tenido relaciones sexuales normales con ese dios, sino que ha sido "tomada" de otro modo, un modo representado muchas veces por una luz y otras por una paloma. El niño crece humano, pero es ese mismo dios, es Dios. Muchas cosas misteriosas, curiosas, milagrosas y mágicas ocurren durante su vida. Eventos prescritos por profetas y visionarios y reproducidos en textos sagrados se cumplen en su persona. Tiene poderes sobrenaturales, como caminar sobre las aguas, transformar el agua en vino, multiplicar el 
pan, resucitar muertos y ver en el futuro; la ley de los hombres lo condena finalmente a la muerte y es crucificado; una vez muerto, aunque, de hecho, es inmortal, desciende a los infiernos donde vence al Diablo, el dios del mal, y luego asciende al Cielo, su hogar, para unirse con su padre, que reina en el Cielo, quien, como se ha dicho, es él mismo..."

Digamos que unos cuantos cientos de millones de seres humanos creen en una construcción que es alguna variante de lo anterior. Algunos creen en esto a medias, por ejemplo, suponen que el relato anuncia una verdad distinta, que no se relaciona con el mundo en forma simple. Pero, la mayoría cree realmente que el párrafo refiere hechos reales, ocurridos en un lugar y en un tiempo real, con seres reales.

Compárese ahora el primer párrafo, sobre los extraterrestres, que nos servía de estímulo jocoso, con lo que se sostiene en este segundo párrafo.

Adelantémonos a desalentar eventuales irritaciones. El ejercicio intelectual que nos ocupa es otro. Igualmente, como se entiende, no se trata de un recuento fiel de la creencia cristiana en su totalidad. Lo que se expuso es un trozo menor, una representación parcial de la creencia. El punto que requiere nuestra atención es otro. Las doctrinas de los extraterrestres pueden y de hecho suelen ser bastante más sofisticadas que la caricatura expuesta, sin dejar de contener hechos como los que se relatan y de ser esos hechos u otros similares los que se sostienen en forma medular en la propuesta total.

La crítica no se refiere a la fe religiosa, sino a la convicción de que el párrafo que nos sirve de ejemplo relata hechos, acontecimientos verdaderos, sobre los que hay evidencias, testigos, efectos, etc. y en los que podemos confiar en forma garantizada, resuelto en forma satisfactoria todo cuestionamiento de la plausibilidad de lo que se afirma. Y, también, que podemos esperar convencer en forma racional a una persona, digamos, a un chino o a un marciano que jamás haya escuchado de Jesús, sobre la veracidad de estos hechos y la realidad de los eventos aludidos (y no sobre la religiosidad del relato y el potencial ético, estético, místico y espiritual en general de los contenidos).

\subsubsection{Universos argumentales}

Pero, notamos que algo está ocurriendo en la comparación entre el episodio de aterrizaje extraterrestre y el episodio del dios nacido hombre. Una tensión separa los ámbitos en cuestión y parece trabar el tránsito de un ámbito a otro bajo estándares comunes de sensatez: estamos dispuestos a tolerar este último, sin cuestionar su racionalidad factual, mientras que el primero es sometido a una revisión de cordura, de seriedad, de pertinencia, de objetividad y factualidad. Al parecer, hay planos distintos implicados. Pero, ¿cuál es el estatus ontológico de estos planos? Aquel se inscribe en un universo religioso: los hechos relatados caen, por así decirlo, bajo la jurisprudencia de la fe. No se trata de una racionalidad que recurra a la ciencia y a la experiencia. El apoyo de esa construcción se relaciona con textos sagrados, creencias, templos, sacerdotes, ritos, ceremonias, instituciones, envestiduras, entre otras formas de apoyo social para la construcción religiosa. En cambio los hechos de los extraterrestres se inscriben en el ámbito de autoridad de la ciencia y la experiencia. Los personajes encargados no son los sacerdotes, sino los científicos, y también nosotros mismos, como testigos de una experiencia cotidiana que no se condice con ese relato. En ambos casos, sin embargo, los hechos relatados se postulan como verdaderos, reales. 
Y esta simple y obvia imparidad es lo que debe llamarnos la atención, a saber, que hay un relato patentemente inverosímil, de inadmisibles recuentos, que recibe aceptación factual por vía de una larga tradición religiosa, en tanto hay otro, posible, pero improbable, que es rechazado desde la tradición científica por su pésima calidad factual.

Nótese que estos ámbitos o universos distintos del discurso argumentativo no se molestan en el diario vivir: un científico, de hecho, la gran mayoría de los científicos occidentales, no vive una contradicción aflictiva entre su creencia en los hechos en torno al dios hombre, por un lado, y su rechazo a la visita de extraterrestres, por el otro, a pesar de que, en términos de la racionalidad en los hechos, este último, si bien no se sustenta en los hechos, es posible y compatible con nuestra experiencia cotidiana, en tanto que el anterior no lo es en absoluto.

\section{Otros movimientos patológicos}

\subsection{Evasiones}

Por el papel dialógico y dinámico que cumplen, las patologías pueden muchas veces caracterizarse como "evasiones": son mecanismos del orador para evadir su responsabilidad del peso de la prueba en una discusión, en un debate, en una riña, en una disputa, en un intercambio de opiniones. Algunos son apenas trucos, pequeños movimientos falaces. Otros son principios de rendimiento mayor en el comportamiento humano.

Algunos de los nombres propuestos apuntan a falacias establecidas en la tradición. Obviamente, no son categorías que puedan aspirar a formar parte de una lista finita o siquiera coherente de "enfermedades" o debilidades discursivas. No tienen otro valor teórico que el de sondear un territorio: no nombran nada de mayor estabilidad objetiva o empírica, si bien los principios involucrados, cuya complejidad apenas sondeamos y cuyo número no presenta un límite, son, por fuerza conceptual, mecanismos naturales de funcionamiento racional.

\subsubsection{La excusa práctica}

Este truco es un modo frecuente de evasión. Se nos impone a veces, por ejemplo: "No es este el lugar para extendernos en la demostración de este principio". Y, en casos, el principio justamente es el asunto que requiere nuestro tiempo. Variantes de lo anterior son: "En el escaso espacio que tenemos, no podremos elaborar sobre esta bien confirmada afirmación." Y, por no estar alerta, pasa inadvertido el hecho de que tal afirmación simplemente no ha sido confirmada en absoluto.

\subsubsection{Circularidad argumental}

Es un movimiento mayor para la evasión del asunto. Muchas veces tiene la forma de una trampa analítica. Por ejemplo, se sostiene que "el Ministerio de Educación vela por el bienestar de los estudiantes" y, ante el cuestionamiento, o para reafirmar, se propone como argumento que "[...] el Ministerio vela por la calidad de la educación en el país y como el bienestar estudiantil es parte de esa calidad entonces el Ministerio vela por el bienestar de los estudiantes". Como vemos, si aceptamos la Garantía hemos aceptado la conclusión, porque la primera implica la segunda. Pero, es justamente la afirmación de la Garantía lo que 
está en cuestión. El argumento es circular: la conclusión ya estaba en una de las premisas: si aceptamos que el Ministerio vela por la calidad de la educación ya hemos aceptado la implicación semántica de que el Ministerio vela por el bienestar de los estudiantes.

Advirtamos, nuevamente, que el principio en síno es patológico. Muchos procedimientos de definición y aplicación de términos, de estipulación y aplicación de norma, de institución y procedimiento, en general, presentan este carácter de lo circular. El jurista recurre muchas veces al diccionario para buscar allí una autoridad en la interpretación de los términos, y en estas definiciones no hay otra cosa que nuevos términos que requieren de definiciones, las cuales a su vez están compuestas de nuevos términos, ad infinitum. Aún así, el jurista puede basar su alegato en forma justificada a partir de definiciones del diccionario. Los códigos legales suelen tener igualmente circularidad inscrita en sus textos, sin presentar su uso necesariamente una jugarreta analítica por parte del jurista.

\subsubsection{Irrelevancia argumental}

Es otro conjunto de tipos de evasión, en el que se cambia la perspectiva y a veces el campo argumental. En un sentido, se trata de tipos de evasión flagrante, por lo que son candidatos a prototipos en esta función. Por ejemplo, se discute una ley que obliga al empleador a destinar parte de las ganancias producidas por el trabajo empleado en mejorar las condiciones laborales de su empresa. Un senador se opone a esa ley alegando: "porque yo siempre he sostenido que el trabajo es un derecho de todos..." Ese derecho no estaba en juego en la discusión. Sin embargo, se establece una apariencia de relevancia en una suerte de entimema o argumento insinuado: si pasa esta ley, habrá una dificultad adicional en la creación de empleos; por ello, habrá menos oferta de empleo, por lo que habrá más desempleados, de modo que el principio del derecho universal al trabajo se ve en peligro, lo que no ocurre si no pasa esta ley...

\subsubsection{Pegados tendenciosos}

A asuntos establecidos se pegan otros que, por la calidad de firmeza de los primeros, parecen igualmente firmes. Por ejemplo, en un sistema de libre mercado laboral, a mayor oferta de mano de obra más bajo es el sueldo por el empleo. El asunto es un principio establecido que describe un funcionamiento en esas condiciones. Pero alguien nos trae la noticia de que el trabajo es por naturaleza un producto en el mercado de las ofertas y demandas y, por ello, el hombre está sujeto a ofrecer su mano de obra al precio que fija el mercado. Se han pegado dos asuntos que no están unidos en la naturaleza, sino sólo en un discurso tendencioso. Que los ríos van a dar a la mar es un hecho; no por ello dejamos de regar las siembras con su agua, de construir represas, puentes, canales. El sistema de libre mercado es una abstracción económica, un río en un tubo de ensayo con el que podemos operar como nos plazca. En esa abstracción se produce, entre otros, el efecto citado de la oferta y la demanda de los productos. Pero que el trabajo del hombre sea de hecho un producto en esas condiciones depende de nosotros, no de las condiciones.

\subsubsection{Desvío desfavorable a la persona}

Se trata de otro conglomerado discursivo que evade la responsabilidad de la prueba. Esta vez, la evasión se produce por el expediente de rasgos que se le atribuyen a la persona que argumenta, los que, sin embargo, no son relevantes para el asunto tratado: "No podemos 
considerar seriamente el proyecto de recreación juvenil del arquitecto Ramírez: todos sabemos que él es homosexual". "Sabemos que el Señor Pérez ha estado preso por estafa: ¿cómo podemos entonces atender a su propuesta de organizar el Centro de Padres de esta escuela?" El ataque a la persona, en sus infinitas variantes, se da en forma más o menos directa. Se da, por ejemplo, el cuestionamiento directo de la integridad moral de un interlocutor; se busca de ese modo invalidar toda propuesta suya, por carecer de credibilidad la persona. También, está la revelación de propósitos egoístas del proponente, omitidos, o consecuencias ventajosas para él, que se siguen de su propuesta; se pretende, así, invalidar la propuesta por parcialidad en el razonamiento y por conveniencia personal.

\subsubsection{Desvío favorable a la persona}

Es la contrapartida positiva de lo anterior. Se trata de evadir el peso de la prueba por el expediente de rasgos favorables que se adjudican al argumentador: "El Señor Gutiérrez es un padre de familia, una persona seria y responsable. Su propuesta de crear un estacionamiento en el lugar de la cancha de fútbol es una propuesta seria y responsable." "Conocemos la impecable trayectoria de excelencia académica del Profesor Doctor Chamullo; la integridad y sabiduría de su propuesta nos hace apoyarla sin reserva alguna." Este conjunto de giros lleva el nombre genérico de "argumento por autoridad." Se evade el peso de la prueba apelando a la autoridad en una persona, sea ésta una envestidura, un título, un grado, un nombramiento honorario, una tradición, un reconocimiento, todo lo cual no viene realmente al caso, pero pesa como el plomo mismo en la balanza de la persuasión. La audiencia está dormida, y estos son, justamente, estribillos que la mantienen en ese estado de indolencia; el retórico que aborrecemos los conoce por instinto, y los canta para acunar el sueño de sus víctimas.

\subsection{Principio y aplicación}

Lo que vemos en estos apartados sobre "patología argumental" es que se trata de una serie de principios de la cognición práctica que de algún modo funcionan mal. Y advertimos que lo patológico no son estos principios, sino el uso que se hace de ellos. El principio, en sí, es un modo de operar. Funciona perfectamente en algunas circunstancias, no tan bien, y mal, en otras. Transformado el asunto de las patologías argumentales a "uso inadecuado de principio", se mueven los cuestionamientos al ámbito de la aplicación o uso de los principios. Y notamos que el modelo de análisis que aplicamos es una buena herramienta para diagnosticar "inadecuación en empleo del principio". Repasemos otros.

\subsubsection{Blanco o negro}

Nos dicen, por ejemplo:

"o el hombre es bueno o es malo por naturaleza, y, considerando las atrocidades a lo largo de la historia, vemos que no es bueno. De modo que el hombre es por naturaleza malo. Debemos, entonces, ..."

A esto suele seguir una cadena nada inocente de nuevos sofismas y malabares que van a dar en la oferta de una nueva gimnasia curativa, un grupo esotérico de reclusión en las montañas, una nueva planta medicinal de antiguo uso aborigen, un texto de guía espiritual para 
la liberación del alma de la corrupción corporal, o, más frecuentemente de lo que se espera, van a dar a una que otra cátedra en nuestras universidades. El truco aquí consiste en la primera imposición disyuntiva, que se filtra de modos más o menos sutiles en nuestro consentimiento: O esto es así o es asá. Y resulta que la dicotomía no es tal. En nuestro ejemplo (demasiado tosco para un sofista de carrera) que el hombre o es bueno o es malo por naturaleza.

El esquema de razonamiento pertenece a la cognición práctica. Es una forma humana de inferir: si es verdad que "o A o B" y se da que "no A", entonces es verdad que "B". El esquema es un hecho de nuestra cognición y converge con los hechos del mundo, cuando éstos son disyuntivos; pero, debemos atender al contexto en el que se le aplica. Es justamente esa inercia de la forma y de suponer verdad en los contenidos, por el solo expediente de decirlos, lo que logra el estado hipnótico que producen estos sofismas.

\subsubsection{Movimientos desde la ignorancia}

Nos encontramos con formas como:

"Por supuesto que hay una vida después de ésta ¿o acaso alguien podría demostrar lo contrario?"

$\mathrm{Y}$ variantes como:

"Seguramente Dios advirtió que la línea de los dinosaurios no conducía al hombre, por lo que los eliminó de la tierra. Es por eso que aún no podemos explicarnos su desaparición repentina."

Este es el principio que nos mueve a dar algo por hecho explicativo de otra cosa simplemente por no tener una explicación a mano. En circunstancias de ignorancia así, si las conjeturas se rigen por estándares de racionalidad local, son sanas y pueden ser útiles. Pero, de nuevo, muchas veces no se revisan los contenidos de las conjeturas, y la forma del esquema impronta la apariencia de verdad en sus contenidos. Veamos una conjetura más cuerda:

"Pese a siglos de reflexión sobre los temas del libre albedrío en la conducta humana, los principios que rigen la voluntad permanecen en el más oscuro misterio. Nuestra inteligencia, debemos concluir, no es capaz de explicar el mecanismo de la voluntad humana."

El anterior es un esbozo de argumento que, por nuestra permanente ignorancia sobre el punto, concluye en una incapacidad o límite de nuestra inteligencia. El esquema es desde la ignorancia, pero la aplicación es sana y puede sustentarse con amplias muestras de intentos incoherentes, fallidos, de dar cuenta racional de la voluntad humana.

\subsubsection{La bola de nieve y la avalancha}

Nos dicen, por ejemplo,

"primero el cigarrillo, luego el alcohol, luego la marihuana y de ahí a la cocaína, la pasta base, la heroína y la prostitución, el robo y la delincuencia. De modo que debemos prohibir la venta de tabaco y alcohol en nuestro país y cerrar así la puerta de entrada a la perdición moral, individual y social" 
Como otros principios del razonamiento, el principio de la bola de nieve es un mecanismo humano para encarar asuntos. Muchas veces funciona bien, pero, otras, nos saca a bailar en el vacío y a darle de palos al aire.

Como siempre, hay que abrir los ojos, mirar el contexto de aplicación, tomarse en serio, y afinar la puntería. No sabemos, por ejemplo, si la relación de secuencia declarada entre tabaco y alcohol es verdadera. Y lo mismo con las otras secuencias implicadas. Especialmente problemáticas parecen las secuencias que saltan de ámbito y pasan del consumo de substancias a oficios y comportamientos estables, como la prostitución, el robo y el delito. ¿De dónde salen esas garantías?

Ahora bien, concediendo, para darle curso a la revisión, la validez de las secuencias (en creciente grado de gravedad o peligro), nos encontramos con nuevas dificultades. Por ejemplo, no sabemos si esa secuencia está unida a otras secuencias o datos importantes para el análisis. Ilustremos: se sostiene que cada uno de los aparentes eslabones de la secuencia inicial son en realidad eslabones en otras secuencias que los contienen en forma natural y establecida y que la cadena inicial es una ilusión. Por ejemplo, nos traen la novedad de que desde el estado de miseria, pasando por el abandono y luego el abuso, se llega a la prostitución y al delito, en un grado significativo y estable de correlación estadística. La cadena inicial propuesta que se nos sugiere ahora, no es una secuencia real: no terminará la prostitución y el delito por terminar con el tabaco y el alcohol, porque los primeros no están ligados, como se pretendía, a estos últimos.

La conclusión trae nuevas complicaciones: no sabemos si lograremos cerrarle la puerta a la perdición con sólo prohibir el tabaco y el alcohol, aun si concedemos la validez o daño real causado por la bola de nieve. Por un lado, efectos y estados complejos en la vida de un individuo, como ser prostituta o delincuente, están ligados a muchos factores, no sólo a una secuencia de escasos elementos, por lo que estos efectos no se reducen o eliminan en forma simple. Y, por otro lado, aun si lográramos reducir los índices a través de la medida, no hemos visto otros efectos que esa medida puede acarrear, efectos que bien podrían invalidar el procedimiento propuesto.

\subsection{Esquema y patología}

¿Cuántos esquemas como los pocos vistos hay? Incontables. Debemos concluir que se trata de una facultad cognitiva que genera infinitas formas, las cuales participan en la producción de nuestra racionalidad cotidiana. El modelo que hemos articulado es un método para recorrer estas formas en sus infinitas manifestaciones. También es un método para evaluar la calidad de la racionalidad producida en los distintos contextos.

\subsubsection{Uno o cero}

Cerremos estos esbozos comentando un par de esquemas. El esquema del tipo blanco o negro instala una premisa mayor o garantía del tipo "x es A o x es B" (implicando "una de las dos y ninguna otra"). Se nos dice, por ejemplo, la mujer es libidinosa o es virtuosa, el gobierno o es honesto o es corrupto, o los hijos salen buenos o salen malos hijos, ¿hay o no hay ciencia en este país?, devolvemos o no devolvemos territorio con salida al mar para Bolivia, ¿es buena o es mala la educación en Chile?, ¿ejercemos o no ejercemos nuestro derecho a respirar aire puro?, el hombre: ¿es racional o es emotivo?, entre infinitas otras manifestaciones del principio del 
blanco o el negro. Vemos en todos estos casos a la premisa en forma disyuntiva: excluyéndose toda otra opción, x es A o x es B. Y apreciamos igualmente que A y B suelen corresponder a calificaciones mutuamente incompatibles aplicadas a la misma cosa, muchas veces polos o extremos distintos dentro de un continuo o a aspectos contrapuestos en algún campo.

Como todo principio de la cognición práctica, el esquema del blanco o el negro es operativo algunas veces. Nos llama a tomar una decisión rápida sobre un asunto basados en un simple indicio, el cual, bajo la jurisprudencia del principio disyuntivo, nos permite concluir en forma expedita sobre un estado de cosas. Por ejemplo, tengo el dato de que el zorro no salió por el otro lado de la madriguera, por lo que retorno a la entrada donde se ha prendido fuego para humearlo. Estoy operando bajo el principio "o el zorro sale por este lado, o sale por este otro". Lo más probable es que el principio me sirva para cazar al zorro. Otras opciones, como que el zorro siga adentro o se haya escapado por arriba, o por otro lado o nunca haya entrado, o esté inconsciente adentro de la cueva, no son tomadas en cuenta al momento de decidir sobre la acción inmediata que me requiere.

Por otro lado, en tanto patología argumental, el problema se presenta en aquellos casos en los que el dilema expuesto no es tal, casos en que existen otras opciones que deben considerarse en el contexto específico de aplicación. La garantía del caso no debería ser operativa, pero está operando. Una vez impuesta o infiltrada como premisa, las conclusiones que se extraen del pivote "x es $\mathrm{A}$ o x es B" pueden establecer la no existencia de un lado demostrando la existencia del otro. Por ejemplo, logro establecer algunos casos de corrupción en el gobierno y, estando concedida la premisa de que el gobierno o es honesto o es corrupto, concluyo que el gobierno no es honesto y que es corrupto. Estoy reduciendo un conjunto de fenómenos complejos -en los que actúan muchos individuos en distintas funciones y con distintas facultades y en los que se articulan muchas instituciones- a una calificación general por medio de un par de datos. Obviamente, la garantía no está justificada, el principio disyuntivo no opera en casos así de complejos y no tengo apoyo que me permita establecerlo como garantía para mis acusaciones. En ese punto, queda expuesto el argumento en su inconsistencia y en su debilidad - una puerta de entrada mortal al ataque contrario-. Por ejemplo, casos de países con documentada certificación de honestidad, en los que se producen igual o mayor número de casos de corrupción que los que se presentan en el argumento inicial. Y es, entre otras cosas, justamente por la aparición y procesamiento judicial de esos casos, que un país se reconoce como honesto. De modo que la garantía no se sostiene. O bien podrían nombrarse casos mayoritarios de honestidad, para demostrar lo contrario de lo que se propone. O bien podría argumentarse desde las leyes y exigir la definición de las calificaciones de "honestidad" y "corrupción" en términos de demandas justificadas, en este caso contra "el gobierno".

\subsubsection{Uno porque no sé que cero}

Los esquemas que producen propuestas basadas en la ignorancia tienen la forma general de "x es A, porque "x no es A" no ha sido demostrado"; o, lo que equivale a lo mismo: "x es A, porque no tengo conocimiento de que no lo sea". Como siempre, el principio es un mecanismo apropiado en incontables ocasiones. Por ejemplo, una madre incluye un repelente de insectos en el equipaje bajo la premisa: hay insectos molestosos en ese camping, lo que concluye por no tener conocimiento contrario. Es un acto justificado desde 
la ignorancia y hay dichos que cristalizan este tipo de conveniencia: "mejor prevenir que jurar", "hombre precavido vale por dos". Voy sediento por el desierto y diviso una manada de gacelas. Pese a costarme mis últimas gotas de energía, sigo su huella bajo la premisa: van donde hay agua. No tengo conocimiento de lo contrario. Veamos ahora un caso patológico. Nos afirma, digamos, un gurú del espacio sideral ante una audiencia estupefacta: "hay vida inteligente en otros planetas; nadie ha demostrado lo contrario y como hay vida inteligente en nuestro planeta, es obvio que ha de haber vida inteligente en otros planetas también." El caso tiene su complejidad. No sólo nos dice que x es A porque no se sabe que no lo sea, sino que además nos presenta un caso en el que, aparentemente, x es A. (Aprovechemos de recordar entre paréntesis que la instalación de estas conclusiones o propuestas en el tipo de discurso que sugerimos suelen acompañarse de cadenas adicionales en las que la conclusión apoya asuntos adicionales, e.g. "[...] Es por eso que debemos comenzar a enviar mensajes a nuestros amigos galácticos...”)

Analicemos: La garantía general es "cuando algo no ha sido demostrado falso, entonces es verdadero"; el dato es que "no ha sido demostrado que sea falso que hay vida inteligente en otros planetas"; la conclusión es que "hay vida inteligente en otros planetas." Pero, el argumento tiene un ciclo inferencial adicional, a saber, el dato que "en nuestro planeta hay vida inteligente". Este último dato, bajo la garantía de que "lo que hay en un lugar se dará también en otros lugares similares", concluye en "la misma" afirmación, a saber, que "hay vida inteligente en otros planetas". Vemos que este segundo ciclo es de forma analógica. De modo que dos procesos inferenciales distintos han dado en una misma forma lingüística, una afirmación que parece ser la misma propuesta. Así expuestos ambos procesos, quedan al descubierto sus debilidades en el contexto de propuesta que revisamos. Específicamente, el carácter gratuito de las dos garantías, el ningún apoyo que presentan y una amplia muestra de ejemplos en los que la ignorancia ha resultado ser una garantía falsa para el establecimiento de certezas.

\section{Rechazado el Proyecto de Ley sobre la Formación de un Ministerio de Salud Discursiva}

Como se aprecia, las patologías pueden identificarse de acuerdo al tipo de debilidad que presentan. En muchas de ellas, por ejemplo, no hay apoyo apropiado a la garantía del caso. De algún modo, la garantía está operando en un contexto en el que de hecho no aplica. La propuesta no ha quedado justificada. Típicamente, esto se va a producir allí donde la garantía queda implícita y no hay apoyo, o bien el apoyo no es explícito, o bien lo es, pero no es relevante, o no logra producir en forma apropiada la garantía que se usa.

El modelo propuesto puede transformarse en un método terapéutico eficaz, un tratamiento contra estos malfuncionamientos de la cognición práctica. Advertimos, empero, que los hechos y la experiencia justifican un cierto escepticismo: Este tipo de terapia apunta a resistir la charlatanería y la propaganda, evita caer en la demagogia o ser víctima de ella, corrige la sofistería, detecta y cura falacias, es antídoto contra ideologías falsas, es antitóxico de la persuasión retórica gratuita, mejora del dogmatismo, ataca cualquier tiranía discursiva, transforma los discursos políticos en extrañas piezas humorísticas... En fin, concluimos que esta terapia será rechazada y condenada por todas las empresas, instituciones e instancias de poder establecidas. 


\section{Bibliografía}

Evans, J, Stephen Newstead \& Ruth Byrne (eds.). 1993. Human Reasoning: The Psychology of Deduction. R.U.: Lawrence Erlbaum Associates Ltd.

Leighton, J. \& Robert Sternberg (eds.). 2004. The Nature of Reasoning. Cambridge: Cambrige University Press.

Marktelov, Ken. 1999. Thinking and Reasoning. R.U.: Psychology Press.

Newstead, S. \& Jonathan Evans. 1995. Perspectives on Reasoning and Thinking. Essays in Honour of Peter Wason. R.U.: Lawrence Erlbaum Associates Ltd.

Rivano, Juan. 1966. Contra Sofistas. Santiago: Talleres Gráficos.

1984. Lógica Práctica y Lógica Teórica. Lund: Ms. Universidad de Lund.

Rivano Emilio. 1999. De la Argumentación. Santiago: Bravo y Allende Editores.

1999. Contra Humanistas. Santiago: Bravo y Allende Editores.

2004. Clases de Pensamiento Crítico. Concepción: Cosmigonon.

Toulmin, Stephen. 1958. The Uses of Argument. NY: Cambridge University Press.

Weston, Anthony. 1992. A Rulebook for Arguments. Indianapolis: Hackett Publishing Company.

Windes, Russell \& Arthur Hastings. 1965. Argumentation as Advocacy. Nueva York: Random House, Inc. 